\title{
SPATIAL ESTIMATION OF EUPHAUSIID BIOMASS ALONG THE PACIFIC COAST OF EASTERN HOKKAIDO, JAPAN IN EARLY SUMMER OF 2008
}

\author{
Naoki Tojo \\ Akkeshi Marine Station, Aquatic Research Station, Field Science Center for Northern Biosphere, Hokkaido University, \\ Aikappu, Akkeshi-cho, Akkeshigun, Hokkaido,088-1113, Japan., bering.raven@gmail.com \\ Kenji Minami \\ Maizuru Fisheries Research Station, Field Science Education and Research Center, Kyoto University, Nagahama, \\ Maizuru-shi, Kyoto, 625-0086, Japan. \\ Ryuichi Matsukura \\ National Research Institute of Fisheries Engineering, Fisheries Research Agency, Hasaki, 7620-7, Kamisu, Ibaraki, \\ 314-0408, Japan. \\ Yohei Kawauchi \\ Graduate School of Environmental Science, Hokkaido University, 3-1-1, Minato cho, Hakodate, Hokkaido, 041-8611, \\ Japan. \\ Tetsuichiro Funamoto \\ Hokkaido National Fisheries Research Institute, Fisheries Research Agency, 116 Katsurakoi, Kushiro-shi, Hokkaido, \\ 085-0802, Japan.
}

See next page for additional authors

Follow this and additional works at: https://jmstt.ntou.edu.tw/journal

Part of the Aquaculture and Fisheries Commons

\section{Recommended Citation}

Tojo, Naoki; Minami, Kenji; Matsukura, Ryuichi; Kawauchi, Yohei; Funamoto, Tetsuichiro; Chimura, Masayuki; Nishimura, Akira; and Miyashita, Kazushi (2011) "SPATIAL ESTIMATION OF EUPHAUSIID BIOMASS ALONG THE PACIFIC COAST OF EASTERN HOKKAIDO, JAPAN IN EARLY SUMMER OF 2008," Journal of Marine Science and Technology. Vol. 19: Iss. 3, Article 9.

DOI: $10.51400 / 2709-6998.2195$

Available at: https://jmstt.ntou.edu.tw/journal/vol19/iss3/9

This Research Article is brought to you for free and open access by Journal of Marine Science and Technology. It has been accepted for inclusion in Journal of Marine Science and Technology by an authorized editor of Journal of Marine Science and Technology. 


\section{SPATIAL ESTIMATION OF EUPHAUSIID BIOMASS ALONG THE PACIFIC COAST OF EASTERN HOKKAIDO, JAPAN IN EARLY SUMMER OF 2008}

\section{Acknowledgements}

Part of this project was involved in the Dymanics of Commercial Fish Stocks (DoCo-FIS) founded by Fisheries Agency of Japan and Assessment of Fisheries Stocks in the Waters around Japan. Hiroshi Matsumoto worked with us for our projects as technicians. Dr. Osamu Shida in Hokkaido Central Fisheries Experiment Station and Dr. Orio Yamamura in HNF guided me in this project. Dr. Hiroto Murase in the Institution of Cetacean Research and Dr. Seiji Katakura provided us variety of advices as mentors in fisheries oceanography. Also, the part of analytical works were possible by supplemental supports upon GIS technologies by project B-0912 of Ministry of the Environment in Akkeshi Marine station, Aquatic research Station, Field Science Center for Northern Biosphere, Hokkaido University

\section{Authors}

Naoki Tojo, Kenji Minami, Ryuichi Matsukura, Yohei Kawauchi, Tetsuichiro Funamoto, Masayuki Chimura, Akira Nishimura, and Kazushi Miyashita 


\title{
SPATIAL ESTIMATION OF EUPHAUSIID BIOMASS ALONG THE PACIFIC COAST OF EASTERN HOKKAIDO, JAPAN IN EARLY SUMMER OF 2008
}

\author{
Naoki Tojo*, Kenji Minami**, Ryuichi Matsukura***, Yohei Kawauchi****, \\ Tetsuichiro Funamoto*****, Masayuki Chimura*****, Akira Nishimura*****, \\ and Kazushi Miyashita******
}

Key words: euphausiid, GIS, spatial estimation.

\begin{abstract}
This study focused on euphausiid distribution and biomass estimation over the coastal shelf of the Pacific coast of Hokkaido Japan in early summer 2008. Acoustic data were obtained in both day (6:00-18:00) and night (18:00-6:00) using a quantitative echosounder (EK60, Simrad) with two frequencies (120 and $38 \mathrm{kHz}$ ). Echoes of euphausiids were specified based on the $\triangle \mathrm{MVBS}$, calculated with seasonal theoretical target strength of Euphausia pacifica. The best-fit kriging models were used to quantitatively interpolate euphausiid distribution. The detected euphausiid biomass reached $38,278 \mathrm{t}\left(>15 \mathrm{gWWm}^{-2}\right)$, suggesting abundant prey for large fishes over study area. On the other hand, the distribution was spatially heterogeneous in produced GIS map, suggesting the spatially limited available prey. Observed day-night difference of estimated biomass was caused by spatial variability of diel movement of euphausiids. Acoustic dead zones and behavioral change in euphausiids may strongly influence biomass estimation in night in coastal shelf environment.
\end{abstract}

Paper submitted 05/31/10; revised 08/30/10; accepted 09/14/10. Author for correspondence: NaokiTojo (e-mail: bering.raven@gmail.com).

*Akkeshi Marine Station, Aquatic Research Station, Field Science Center for Northern Biosphere, Hokkaido University, Aikappu, Akkeshi-cho, Akkeshigun, Hokkaido, 088-1113, Japan.

**Maizuru Fisheries Research Station, Field Science Education and Research Center, Kyoto University, Nagahama, Maizuru-shi, Kyoto, 625-0086, Japan. ***National Research Institute of Fisheries Engineering, Fisheries Research Agency, Hasaki, 7620-7, Kamisu, Ibaraki, 314-0408, Japan.

**** Graduate School of Environmental Science, Hokkaido University, 3-1-1, Minato cho, Hakodate, Hokkaido, 041-8611, Japan.

*****Hokkaido National Fisheries Research Institute, Fisheries Research Agency, 116 Katsurakoi, Kushiro-shi, Hokkaido, 085-0802, Japan.

******Field Science Center for Northern Biosphere, Hokkaido University, 3-1-1, Minato cho, Hakodate, Hokkaido, 041-8611, Japan.

\section{INTRODUCTION}

The Pacific northeast coast of Hokkaido, Japan is called Doto area for the convenience in ecological studies and fisheries $[16,26]$. Coastal shelf and shelf edge of the Doto area is the major fishing ground for commercially important fishes, such as walleye pollock (Theragra chalcogramma) [16]. Especially from April to May, offshore primary production increases up to $>40 \mathrm{mgm}^{-2}$ and sustains following zooplankton bloom in early summer [7]. Life histories of zooplanktons off the Doto area are dependent on offshore productions of western boundary current, Oyashio [18, 20]. Large copepods, such as Neocalanus spp. ascend near surface from April to June then graze the abundant phytoplanktons for following reproductions [19].

Euphausiids observed in the Doto area also depend its reproduction on offshore bloom in early summer $[19,20]$. Pre-spawning aggregation of euphausiids is a fishing target in northern Asia including coastal sea off Sanriku, Pacific coast of northern Japan [20]. In the Doto area, though direct fishing of euphausiids is not common, they still plays significant ecological roll. E. pacifica is one of the most commonly found prey euphausiid species in stomach of young walleye pollock and the other ecologically important fishes, such as Myctophids [26, 24]. Past milestone studies with intensive net sampling have revealed that seasonal change in biomass of $E$. pacifica off coast of Northern Japan [20]. However, extensive discrete net sampling over large and complex costal shelf environment is time and resource consuming. Also, fine information of euphausiid distributions may be lost because of avoidance by euphausiids and mechanical disturbance during sampling. It is meaningful to understand not only the biomass of euphausiids but also their spatial variability and in-situ ecology, in a mesoscale area with continuous dataset under transects.

Acoustic surveys for quantification of euphausiids have been conducted in various sea with the advantage to obtain continuous data set $[2,9]$. There are some euphausiid studies with ecological interpretations in pelagic environment with 


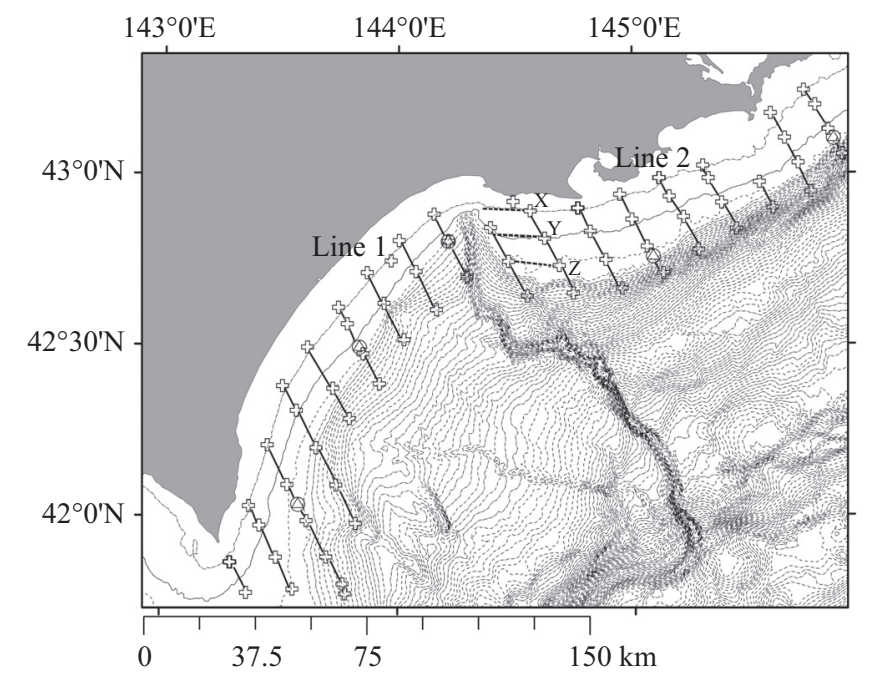

Fig. 1. Study area and survey design in the Doto area. The thick solid lines are main transects, and thick dashed lines are optional transects. CTD stations were indicated as white crosses, and bongo net sampling locations were indicated as circles with triangles. Optional transects were named $X, Y$, and $Z$ from nearshore. Transects used as examples in Fig. 4, line 1 and 2, were also labeled. 50-m isobaths were shown as thin dashed lines. Area between 50 to $150 \mathrm{~m}$ isobath was analyzed in this study.

acoustic survey data $[3,23]$. However, distribution studies of euphausiids over costal shelf using acoustic method have been rare despite of the ecological and economic significance.

Recently, geographic information system (GIS) has been applied to various fisheries and marine ecological studies [1, $14,15]$. It is the advantage that GIS users can overlay spatially corresponding ecological information and produce maps for further discussion for management decisions. Combination of GIS and acoustic methods has been used to analyze ecological mechanism in E. pacifica distribution off northern North Pacific around oceanographic fronts [23]. Moreover, geostatistical techniques, which allows analysts to quantify the patterns of animal distribution, are recently available in common GIS graphic interface. Quantified continuity of animal aggregation is not only useful to estimate its biomass but also to design and to acoustic survey $[5,17]$.

Keeping the above background in mind, goal of this study was estimation of the biomass of euphausiids over the Doto area and interpretation of the distribution using current GIS techniques. Vertical distribution, which is hard to cover by mapping techniques with GIS, was also analyzed by observations of backscattering strength on echograms. Estimated euphausiid biomass was mapped with validation results. Potential ecological distribution determinants was discussed with the produced map.

\section{MATERIALS AND METHODS}

\section{Study Area and Survey Design}

Table 1. Pitch noises recorded in surveys. Reference noises were indicated with asterisks. Absorption coefficients were $0.001004 \mathrm{dBm}^{-1}$ and $0.003049 \mathrm{dBm}^{-1}$ at $38 \mathrm{kHz}$ and $120 \mathrm{kHz}$ frequency channels, respectively.

\begin{tabular}{cccc}
\hline \multirow{2}{*}{ Propeller pitch } & $\begin{array}{c}\text { Vessel speed } \\
\text { (kt, ground speed) }\end{array}$ & \multicolumn{2}{c}{ Frequency channels } \\
\cline { 3 - 4 } & 0 & -161 & -162 \\
\hline-2 & 22 & -162 & -162 \\
0 & 7.8 & -161 & -168 \\
10 & 9.2 & -161 & -164 \\
12 & 10 & -166 & -165 \\
14 & 11.1 & $-162^{*}$ & $-165^{*}$ \\
16 & 11.8 & -161 & -164 \\
18 & & &
\end{tabular}

The study area was coastal shelf from 50- to 150 m-depth sea bottom in the Doto area $\left(4,481 \mathrm{~km}^{2}\right.$, Fig. 1$)$. Acoustic data and the other in situ datasets were collected in summer walleye pollock recruitment surveys in 2008, conducted by Hokkaido National Fisheries Research Institute, Fisheries Research Agency (HNF, FRA) commissioned by the Fisheries Agency of Japan. From June 26th to July 6th in 2008, acoustic survey was conducted with calibrated quantitative echosounder, EK-60 (SIMRAD), on board of RV Kaiyomaru No. 7 (499 t, Nippon Kaiyou Co. Ltd.) with approximately from 10 to 11 knots of cruising speed (Table 1). The 38 and $120 \mathrm{kHz}$ frequencies were used in entire surveys on 18 transects designed nearly orthogonal over isobaths in main surveys (Fig. 1). In optional survey, three parallel transects (line X, Y, Z) to isobaths were designed for the purpose of evaluation of main transect intervals (Fig. 1). The both surveys were conducted in both day (6:00-18:00) and night (18:00-6:00). In main survey, ones in two to three transect lines in night survey, bongo ring net ( $320 \mu \mathrm{m}$ nylon mesh, $70 \mathrm{~cm}$ diameter) was cast to continuous backscattering echoes in $120 \mathrm{kHz}$ echograms to obtain sample specimens (Fig. 1). At every 12 to $13 \mathrm{~km}$ of each transect line, vertical temperature and salinity was measured during daytime survey (Fig. 1). The CTD was cast at the ends of the transect lines, and XCTDs were deployed during cruising on the lines.

\section{Data Processing and Analyses}

The obtained acoustic data were processed using Echoview ver. 4.0 (Myriax software Pty. Ltd.). Elementary Distance Sampling Unit, (EDSU), corresponding to the integration grid of backscattering echoes, was horizontally $50 \mathrm{~m}$. Integration layer thickness within the horizontal grid was set as $5 \mathrm{~m}$, corresponding to the pulse length. Data in upper $150 \mathrm{~m}$ depth layer, excluding from surface to $5 \mathrm{~m}$ depth as dead zone of near surface, was used from consideration in the signalto-noise ratio for further calculation of their biomass based on noises measured in passive mode during cruising in 11 knots. 
Also, all obvious noises during cruising was manually removed from the echograms.

Using the difference in mean volume backscattering strength ( $\triangle \mathrm{MVBS}$ ) of processed data of backscattering echoes at $120 \mathrm{kHz}$ and $38 \mathrm{kHz}$, we specified the grid cells with euphausiids [4]. The range of $\triangle \mathrm{MVBS}$ is theoretically same as the difference of target strength (TS) in different acoustic frequencies:

$$
\Delta M V B S=S v_{120 k H z}-S v_{38 k H z}=T S_{120 k H z}-T S_{38 k H z}
$$

The range of the difference of TS was used to filter cells with specific range of difference of Sv on echograms. The TS at each frequency was calculated using regression models with total length (TL) of specimen based on distorted wave Born approximation [11]. The parameters of the model in June were applied to have consistency with physical properties of euphausids in our survey season. The $>10 \mathrm{~mm}$ TL euphausiids, corresponded the size of adults in specimen, were focused in our analyses considering the morphological change from larval stage influencing the TS calculation. This size threshold was also selected to avoid including small copepods $(<5.0$ $\mathrm{mm}$ ) in our analyses [21]. Using the $10 \mathrm{~mm}$ threshold and maximum TL in subsampled specimen, theoretical range of $\triangle$ MVBS was calculated.

The detected backscattering echoes from euphausiids on echograms were directly observed to understand the vertical distribution and its diel change. Distribution in the echograms between day and night were compared at same transect lines.

Nautical area scattering coefficient $\left(s_{A}, \mathrm{~m}^{2} \mathrm{nmi}^{-2}\right)$ of detected euphausiids for each water column was integrated and organized as database in ArcGIS ver. 9.3 (ESRI). The data tables with $s_{A}$ were converted to point data on ArcGIS analytical platform based on the GPS coordinates. Then, semivariograms [25] were calculated for the plotted $s_{A}$ (Fig. 2). Semivariogram $(\gamma)$ indicates the spatial dissimilarity depending on the distance among the subjects [25]. The equation of $\gamma$ is expressed as:

$$
\gamma(d)=\frac{1}{2|N(d)|} \sum_{N(d)}\left(z_{i}-z_{j}\right)^{2}
$$

where $z$ is the values of $s_{A}$. The $d$ is the unit vector, called lag, between location $i$ and $j$ on transects [25]. The $N(d)$ is the lag average number of data pairs with data belong a lag. Within a lag, obtained highly variable raw values of $\gamma$, is averaged as a empirical semivariogram, $\gamma(d)$. In our analyses, the lag was set in 2,000 m, which include $\geq 40 \mathrm{EDSU}$ on the transect lines. The maximum distance to collect data pairs for calculation was set in $60 \mathrm{~km}$, containing multiple main transect lines anywhere in the study area. In pilot analyses, theoretical semivariograms based on various distribution assumptions were fitted to the empirical semivariograms, and we applied spherical model (Fig. 2) [10].

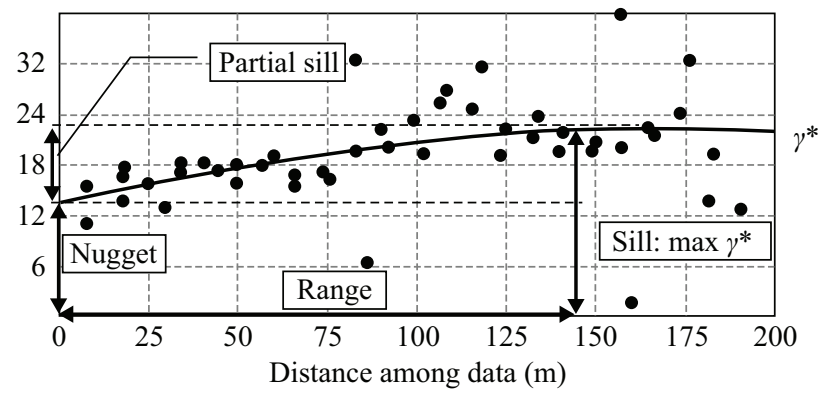

Fig. 2. Example of semivariogram and semivariogram parameters. Black dots are the empirical semivariances $(\gamma)$, and solid line is the theoretical semivariogram of spherical model $\left(\gamma^{*}\right)$. Dashed lines show the range of the partial sill.

The model parameters were calculated from the best fit theoretical semivariogram based on maximum likelihood. These model parameters were used for interpretation of the horizontal distribution of zooplanktons (Fig. 2). Intercept of the theoretical semivariogram, or nugget indicates small scale variability in the acoustic density within lag. The maximum of value in semivariogram is called sill. The difference between sill and nugget is called partial sill, indicating the degrees of spatial variability or trend in the acoustic density depending on the distance. The distance at which the theoretical semivariogram has sill is called range and indicating continuity of the spatial trend. The theoretical semivariograms were compared among optional transect lines between day and night, and the validity of main transect intervals were discussed based on the above distribution characteristics. Then, the best theoretical semivariogram for data from main transects was selected.

Using the selected best theoretical semivariogram, kriging [25] estimation of euphausiid biomass was made. A common 2-D kriging algorithm can be expressed as a weighted interpolation as:

$$
\hat{z}\left(s_{0}\right)=\sum_{i=1}^{n} w_{i} z\left(s_{i}\right)=\mathbf{w}^{\prime} \mathbf{z}
$$

where the $z$ is the $s_{A}$. The is the estimated value at location $\mathrm{s}_{0}$ based on any specific $z$ at location $s_{i}$ spread over area [10]. Bold fonts indicates the matrix. The $z$ indicates data array of $s_{A}$ with spatial coordinates. The weight, expressed as a transposed array $w^{\prime}$ is obtained based on theoretical semivariogram.

Two analytical strata, eastern shelf and western shelf were set because of geographic separation by trench (Fig. 1). Considering in situ distribution of euphausiids observed during surveys as patchy aggregations with many zero observations, we assumed two concepts of distribution: presence or absence of aggregations and density gradients of the present euphausiids over area. Then, the estimation of distribution was made using two-step hierarchical approaches from the former to later concept of the euphausiid distribution. For presence or absence of euphausiids aggregations, overall 


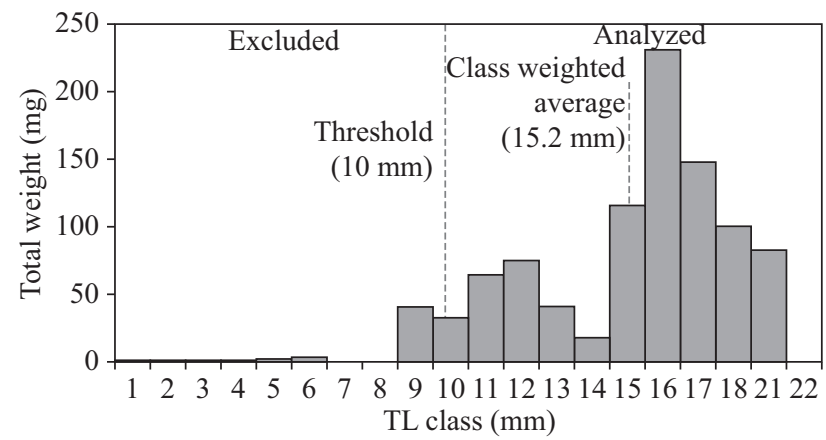

Fig. 3. Bar graph of sum of weights for size classes of Euphausia pacifica.

acoustic density on transects were transformed into normal score based on its frequency distribution. The probability of aggregation occurrence over area was estimated using kriging. The threshold between presence and absence was set at zero density where 0.5 of probability of occurrence ranging from 0 to 1.0 . The area with $>0.50$ of probability was defined as where euphausiid aggregations were present. The density gradients of euphausiids were estimated using ordinal kriging with present acoustic density. The $s_{A}$ was natural $\log$ transformed to attain normality. Interpolated density gradients within the area with $<0.50$ of probability of occurance were excluded from our analyses as absent.

To scale acoustic density, weighted average of TL by weights in subsampled specimen was used to calculate representing TS of the detected euphausiids. Geostatistically interpolated acoustic density was mapped in the unit of $\mathrm{gWWm}^{-2}$. Biomass estimation from interpolated acoustic density was made using spatial analyst extension of ArcGIS. To integrate the euphausiid biomass over study area with least spatial bias, Albers equal area projection was used as the map projection of GIS platform [22]. The prediction errors were evaluated on the error map, and interpolation performance was validated in manner of leave-one-out cross validation (LOOCV).

\section{RESULTS}

\section{Acoustic Sizes and Detected Echoes}

Specimen samples were total $1,162 \mathrm{~g}$. More than $85 \%$ of them were euphausiids and $<2 \mathrm{~mm}$ copepods. Of $8 \mathrm{~g}$ subsampled euphausids, the $>10 \mathrm{~mm}$ euphausiids were $1.16 \mathrm{~g}$ (569 individuals). Maximum TL $\mathrm{mm}$ was $21.3 \mathrm{~mm}$, and the weighted average of TL was $15.2 \mathrm{~mm}$ (Fig. 3). Calculated representing TS was -90.2 and $-104.8 \mathrm{~dB}$ for $120 \mathrm{kHz}$ and 38 $\mathrm{kHz}$, respectively, and the obtained range of $\triangle \mathrm{MVBS}$ was from 13.1 to $16.4 \mathrm{~dB}$ based on the statistics of the subsampled specimens (Table 2). The individual weight of the representing size of $>10 \mathrm{~mm}$ euphausiids was $27.6 \mathrm{mg}$ based on significant cubic relationship $\left(P<0.05, r^{2}=0.95\right)$ between TLs and body weights, BW, expressed as:

$$
B W=0.0075 T L^{3}
$$

Table 2. The calculated target strength (TS) for each frequency and difference in mean volume back scatterings ( $\triangle M V B S)$ calculated from difference of TS.

\begin{tabular}{lcccc}
\hline \multicolumn{1}{c}{ Size } & \multicolumn{1}{c}{$\mathrm{TL}$} & $\mathrm{TS}_{120 \mathrm{kHz}}$ & $\mathrm{TS}_{38 \mathrm{kHz}}$ & $\Delta$ MVBS \\
\hline Maximum & $21.3 \mathrm{~mm}$ & -83.4 & -96.5 & 13.1 \\
Representing & $15.2 \mathrm{~mm}$ & -90.2 & -104.8 & 14.6 \\
$10 \mathrm{~mm}$ & $10 \mathrm{~mm}$ & -98.7 & -115.1 & 16.4 \\
\hline
\end{tabular}
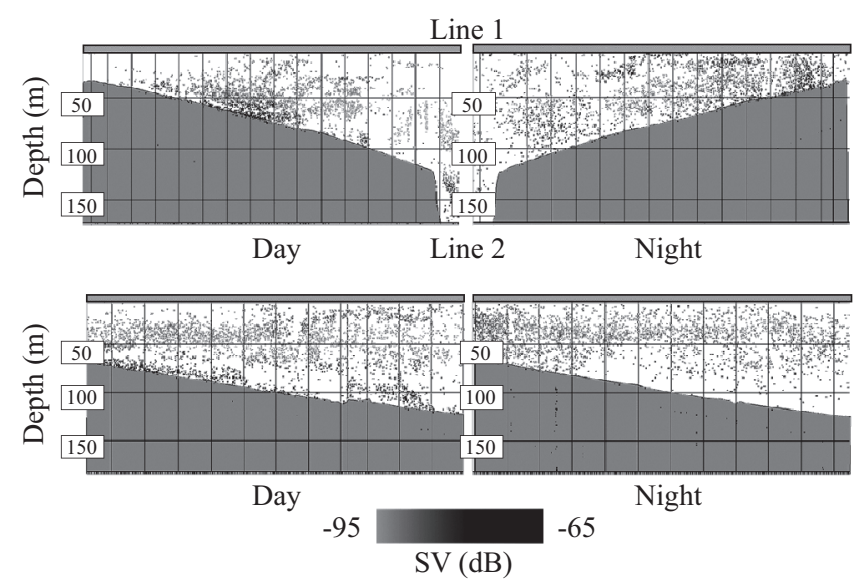

Fig. 4. Example echograms of detected euphausiids at line 1 and 2 in Fig. 1.

Detected euphausiid echoes were mainly present near bottom and stronger in day time than in night time (Fig. 4). The echoes in night echograms were dispersed over coastal shelf. Under the transect lines over narrow coastal shelf, coastward shift of echoes were distinct in night (Fig. 4).

\section{Horizontal Distribution}

Empirical semivariograms were highly variable off the theoretical semivariograms for probability of aggregation occurrences (Fig. 5). Temporal changes in distribution trend were observed between day and night in both coastal shelves. All theoretical semivariograms in the night had smaller partial sills than nugget, indicating less spatial trend in detected euphausiid distribution over study area in nighttime than daytime. The theoretical semivariogram of optional transects had nuggets close to zero excepting it for the presence data in daytime, and the distinct partial sills suggested relatively large spatial trend in direction along isobaths (Table 3(a)). Ranges of optional transects were often shorter than $10 \mathrm{~km}$ (Table $3(b))$. Especially along offshore lines in daytime and nearshore lines in night time, ranges were distinctly short $(<8 \mathrm{~km})$.

The produced distribution maps were different between day and night. In day time, the presence of euphausiids was contenuous over both eastern and western shelf (Fig. 6(a)). On the other hand, it was sparsely distributed over shelf in night time (Fig. 6(b)). Dense euphausiid aggregations were observed over western shelf and shelf edge of eastern shelf in day time. 
Table 3. Semivariogram parameters of optional transects, $X, Y$, and Z (Fig. 1): (a) probability of aggregation occurrence and (b) abundance with present data.

(a)

\begin{tabular}{|c|c|c|c|c|c|c|c|}
\hline \multirow{2}{*}{ Daytime } & \multicolumn{3}{|c|}{ Line } & \multirow{2}{*}{ Nighttime } & \multicolumn{3}{|c|}{ Line } \\
\hline & $X$ & $\mathrm{Y}$ & Z & & $X$ & $\mathrm{Y}$ & Z \\
\hline Nugget & 0.02 & 0.18 & 0.11 & Nugget & 0.06 & 0.17 & 0.11 \\
\hline Partial sill & 0.01 & 0.08 & 0.21 & Partial sill & 0.02 & 0.14 & 0.06 \\
\hline Range & 21587 & 5168 & 14152 & Range & 17720 & 13544 & 17263 \\
\hline \multicolumn{8}{|l|}{ (b) } \\
\hline \multirow{2}{*}{ Daytime } & \multicolumn{3}{|c|}{ Line } & \multirow{2}{*}{ Nighttime } & \multicolumn{3}{|c|}{ Line } \\
\hline & $X$ & $\mathrm{Y}$ & Z & & $X$ & $\mathrm{Y}$ & Z \\
\hline Nugget & 3.42 & 0.95 & 1.71 & Nugget & 0.00 & 0.00 & 0.08 \\
\hline Partial sill & 0.00 & 1.05 & 3.93 & Partial sill & 9.15 & 1.65 & 11.48 \\
\hline Range & 18826 & 7184 & 5456 & Range & 6172 & 3635 & 12410 \\
\hline
\end{tabular}
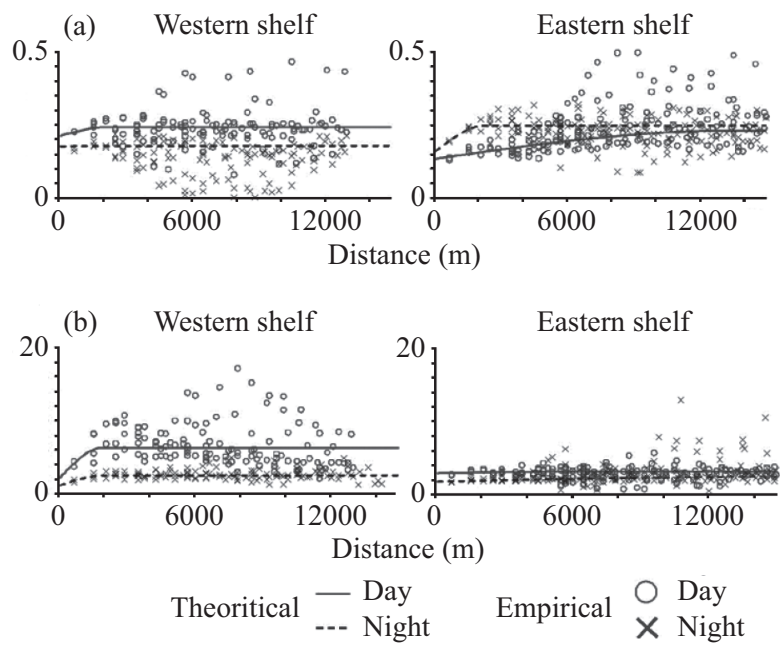

Fig. 5. (a) Semivariograms for probability of aggregation occurrences and (b) abundance with presence data of eastern (right) and western (left) shelves.

Where euphausiids were present in night time was limited at middle of shelves (Fig. 6(b)).

Biomasss of detected euphausiids over study area were $38,278 \mathrm{t}$ (average area density $=15.0 \mathrm{gWWm}^{-2}, \mathrm{SD}=20.6$ ) and $1,620 \mathrm{t}\left(0.64 \mathrm{gWWm}^{-2}, \mathrm{SD}=1.5\right)$ in day and night, respectively. The area where euphausiid detected were $56 \%$ of the study area $\left(2,506 \mathrm{~km}^{2}\right)$ in daytime and $27 \%$ of the study area $\left(1,221 \mathrm{~km}^{2}\right)$ in nighttime. Western shelf had higher area density per area $\left(22.2 \mathrm{gWWm}^{-2}, \mathrm{SD}=21.6\right)$ than eastern shelf $\left(4.4 \mathrm{gWWm}^{-2}, \mathrm{SD}=17.3\right)$. The large SDs indicate the high spatial variability in distribution of euphaussiid aggregations over both shelves. Standard errors of prediction tend to be high where euphausiids were less observed in day; the standard errors in unit of individual euphausiid reached $>100$ over eastern shelf (Fig. 7). Patches of moderate standard error of prediction were observed in night time. Percent of concordance of presence or absence were $>75 \%$ (Table 4 ). Root

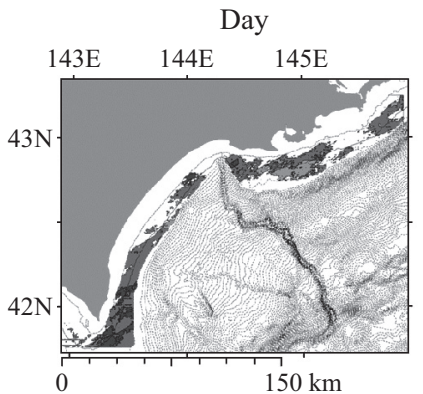

(a)

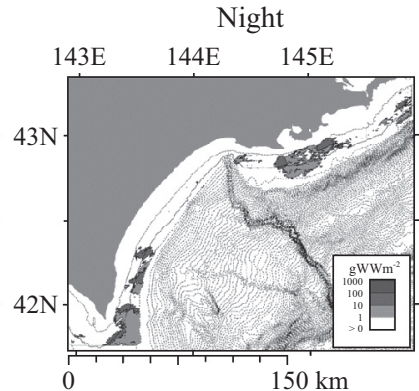

(b)
Fig. 6. Developed distribution maps of $>10 \mathrm{~mm}$ euphausiids over the study area in (a) day and (b) night. 50-m isobaths from were shown as thin dashed lines. Area between 50 to $150 \mathrm{~m}$ isobath were analyzed in this study.

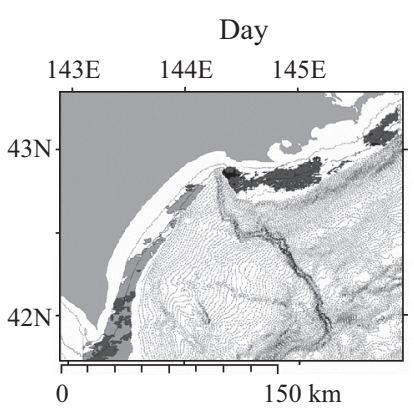

(a)

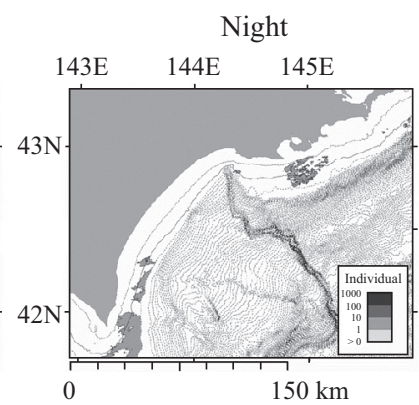

(b)
Fig. 7. Standard error map for estimated distribution of $>10 \mathrm{~mm}$ euphausiids over the study area in unit of individual numbers of euphausiids in representing size. 50-m isobaths were shown as thin dashed lines. Area between 50 to $150 \mathrm{~m}$ isobath were analyzed in this study.

mean squared of errors (RMSE) of LOOCVs was relatively high especially in western shelf, indicating lowered performance of interpolation where euphausiids were densely aggregated (Table 4). 
Table 4. Results of leave-one-out cross validation for interpolations: concordance of presence absence (CPA, $\%)$ and root mean squared of error (RMSE).

\begin{tabular}{ccccc}
\hline & \multicolumn{2}{c}{ Day } & \multicolumn{2}{c}{ Night } \\
\cline { 2 - 5 } & West & East & West & East \\
\hline CPA $(\%)$ & 89 & 78 & 82 & 80 \\
RMSE $\left(\mathrm{gm}^{-2}\right)$ & 53.3 & 26.9 & 6.6 & 12.1 \\
\hline
\end{tabular}

\section{DISCUSSION}

Euphausiid biomass was estimated using integrated procedure with acoustic surveys and GIS analyses. Not only biomass was estimated, but also the spatial variability in euphausiids was visualized as maps with quantitatively validated information in a mesoscale covering the Doto area. Spatial variability of zooplanktons including euphausiids would influence the potential fishing grounds supported by these preys. The provided maps and estimation methodology provide supplemental information to make decisions for managers, such as delineating fishing management area in the Doto area.

On the other hand, distinct difference in estimations between day and night may be required to discuss for the further applications of our results. The estimated biomass was oneorder different between day and night. Observed euphausiids including E. pacifica are characterized the diel vertical migration in their life history [19]. During daytime, the euphausiids aggregates near bottom then ascend to surface with dusk and actively feed $[6,13]$. In the echograms with detected euphausiids, upward shift of vertical distribution in the night was also observed. On the other hand, the echoes were less distinct and spatially sparse (Fig. 4). The unobvious distribution characteristics represented by the semivariogram parameters of euphausiid distribution in night suggests that detected euphausiid echoes lost spatial variability and continuity. The euphausiid biomass based on the spatial trend was also underestimated in nighttime because of the lowered detections under transect.

Used calculation model of TS was based on average swimming angle of E. pacifica in tank experiment $[11,12]$. It is still unknown that the swimming angles of euphausiids during feeding or ascending near surface. The individual swimming angles during various activity in night time is probably variable, so the used $\triangle \mathrm{MVBS}$ range may have not been sufficient to detect the euphausiids from night backscattering. The behavioral changes of euphausiids between day and night also change the orientation of them. Considering the Rayleigh scattering with small objects as euphausiids, sparse distribution with stochastic orientations of them in night time would lower the detection of aggregations at $120 \mathrm{kHz}$ frequency. Near-bottom dead zone may bring the underestimation of the absolute biomass of euphausids in daytime. However, dense daytime echoes in water column are more appropriate as data

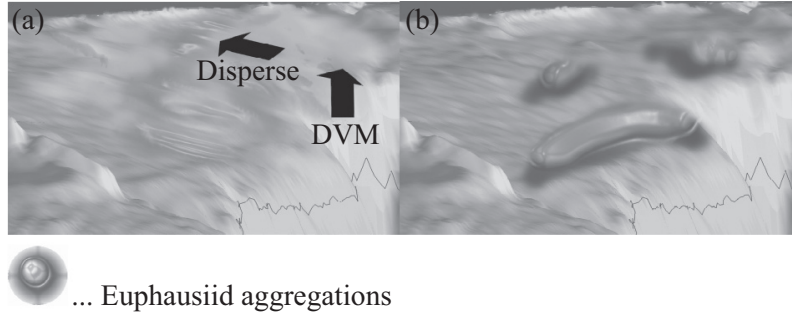

Fig. 8. Schematics of distribution scenario in study area of the Doto area. (a) The active vertical migration (diurnal vertical migration, DVM) enhances spreading over coastal shelf with extension of Oyashio water in nighttime. In daytime, (b) descended euphausiids aggregates local basins and valleys on shelf environment.

to estimate the relative magnitude of euphausiid biomass than sparce nighttime echoes.

Acoustic dead zone near surface is the other influential cause of lowered estimated biomass via lowered detections. The echoes aggregated near surface $(<5 \mathrm{~m}$ depth) in night time (Fig. 4). The influence of dead zone at surface upon biomass estimations is probably larger in night time than day time. Assuming euphausiid density in dead zone at bottom was constant over the Doto area, overall large euphausiid biomass $(>10 \mathrm{~mm})$ was $>15 \mathrm{gWWm}^{-2}$ based on the day time estimation.

In corresponding season to our survey in 2008, 1-year old walleye pollock over the Doto area was approximately $7,000,000$ individuals (T. Funamoto, unpublished). The average weight of the 1-year old walleye pollock was $50 \mathrm{~g}$. Yoshida and Sakurai [27] suggested that the maximum food consumption of walleye pollock as $11.8 \%$ of the body weight per day. In the case of that the 1-year old walleye pollock was evenly distributed over the Doto area, $0.09 \mathrm{gm}^{-2}$ of food would be daily consumed based on these references. Our estimated euphausiid biomass exceeded the expected food for the earliest age walleye pollock in the area in the same survey season of 2008. However, the found spatial variability of euphausiid distribution over area suggested potential local scarcity of prey. Additionally, species depending upon euphausids are not only walleye pollock, and the found spatial variability may bring potential inter- and intra-specific competition over specially limited euphausiids [21].

The sources of euphausiids' spatial variability probably related to the shoreward transportation of offshore water because of their life history belong to offshore environment [20]. Observed upward and shoreward movement of detected euphausiid echoes suggest that the passive shoreward transportation enhanced by the active diurnal vertical migration (Fig. 8). Offshore euphausiids around the Doto area ascend near surface in night time, and transported to shallow area of coastal shelf (Fig. 8(a)). In daytime, they aggregate near bottom probably where small basin or valleys were available though some may be transported back to offshore environment depending on the tidal forces (Fig. 8(b)).

In the past, the Oyashio water dependency of both vertical 


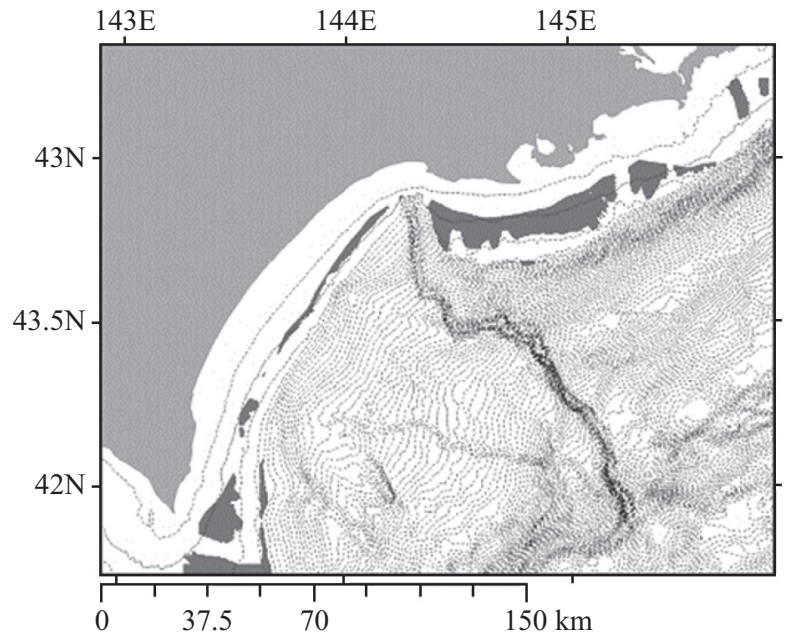

Fig. 9. A map produced from extended analysis with conditioned indices of Oyashio water (> 33 PSU) and fine scale basins over shelf scored depending on the inclinations with statistical quantiles. Shaded area were selected under conditions of presence of $>33$ PSU water over bottom and relatively deep ( $>50$ percentile) the scored basins in 5-km resolution. 50-m isobaths from were shown as thin dashed lines. Area between 50 to 150 isobath were analyzed in this study.

and horizontal euphausiid distribution was already suggested in Doto area in early summer [21]. The localities of euphausiids were most likely enhanced by bathymetric influences to transportation from offshore Oyashio passage near the Doto area (Fig. 9) [8]. The local basins and valleys of the Doto area work as local aggregation sinks of transported euphausiids in day time and probably providing potential feeding ground for the fishes including walleye pollock.

Suggested errors were large and spatially stochastic (Table 4, Fig. 7). The empirical semivariograms were off the bestfit theoretical semivariogrtams, The fine scale dynamics of euphausiid distribution can be the source of the errors. Local bathymetry and oceanography may influence upon the stationality of euphausiid distribution and cause local over- and underestimations. For future improvement of biomass estimation with geostatistical approach as this study, flexible methods to spatial variability of animal distribution should be applied. For example, improvement of the theoretical semivariogram models based on in situ complexity, such as models using directional effect (anisotropy) and multivariate analysis [25]. However, only analytical methodology does not resolve the found impact of spatial complexity upon estimation; survey designs based on the given spatial complexity need to be investigated to obtain estimations of euphausiids and the other prey planktons supporting the Doto area fishes and fisheries. The current designs of transects for walleye pollock recruitment may not appropriate for zooplankton biomass estimation (Table 3b). Use of supplemental transects over the potential aggregation sinks or adoptive samplings near the found sink would improve the estimation of prey biomass including euphausiids.
In addition, influence of acoustic dead zone was not adjusted for biomass estimation in this study. Further investigation of euphausiids or zooplankton density in acoustic dead zone in both surface and bottom may allow researchers to estimate more precise estimation of their biomass using acoustic methods and managers to decide the fishing areas.

\section{ACKNOWLEDGMENTS}

Part of this project was involved in the Dymanics of Commercial Fish Stocks (DoCo-FIS) founded by Fisheries Agency of Japan and Assessment of Fisheries Stocks in the Waters around Japan. Hiroshi Matsumoto worked with us for our projects as technicians. Dr. Osamu Shida in Hokkaido Central Fisheries Experiment Station and Dr. Orio Yamamura in HNF guided me in this project. Dr. Hiroto Murase in the Institution of Cetacean Research and Dr. Seiji Katakura provided us variety of advices as mentors in fisheries oceanography. Also, the part of analytical works were possible by supplemental supports upon GIS technologies by project B-0912 of Ministry of the Environment in Akkeshi Marine station, Aquatic research Station, Field Science Center for Northern Biosphere, Hokkaido University.

\section{REFERENCES}

1. Burrows, M. T., Harvey, R., and Robb, L., "Wave exposure indices from digital coastlines and the prediction of rocky shore community structure," Marine Ecology Progress Series, Vol. 353, pp. 1-12 (2008).

2. Cochrane, N. A., Sameoto, D. D., and Herman, A. W., "Scotian Shelf euphausiid and silver hake population changes during 1984-1996 measured by multi-frequency acoustics," ICES Journal of Marine Science, Vol. 57, No. 1, pp. 122-132 (2000).

3. Coyle, K. O., "Acoustic estimates of zooplankton biomass and distribution: application of canonical correlation to scaling of multifrequency acoustic data," Canadian Journal of Fisheries and Aquatic Sciences, Vol. 57, No. 11, pp. 2306-2318 (2000).

4. Everson, I., Goss, C., and Murray, W. A., "Comparison of krill (Euphausia superba) density estimates using 38 and $120 \mathrm{kHz}$ echosounders," Marine Biology, Vol. 116, pp. 269-275 (1993).

5. Honda, S., Estimation of Year-Class Strength in the North Pacific Stock of Walleye Pollock (Theragra chalchogramma) Based on Hydroacoustic Surveys, Ph.D. Dissertation, Department of Fisheries Science, Hokkaido University, Hakodate, Japan (2003).

6. Iguchi, N., "Spring diel migration of a euphausiid Euphausia pacifica in Toyama Bay, southern Japan Sea," Bulletin of Japan Sea National Fisheries Research Institute, No. 45, pp. 59-68 (1995). (in Japanese)

7. Kasai, H., Saito, H., and Tsuda, A., "Estimation of standing stock of chlorophyll a and primary production from remort-sensed ocean color in the Oyashio region, the western subarctic Pacific, during the spring bloom in 1997," Fisheries Oceanogrphy, Vol. 54, No. 5, pp. 527-537 (1998).

8. Kusaka, A., Komori, T., Azumaya, T., Kasai, H., Koguma, Y., Kawasaki, Y., and Hirakawa, K., "Seasonal variability of marine environmental structure in Doto area," Oceanography in Japan, Vol. 18, No. 2, pp. 135 156 (2009). (in Japanese)

9. Lawson, G. L., Wiebe, P. H., Stanton, T. K., and Ashjian, C. J., "Euphausiid distribution along the Western Antarctic Peninsula-Part A: Development of robust multi-frequency acoustic techniques to identify euphausiid aggregations and quantify euphausiid size, biomass, and biomass," Deep Sea Research Part II, Topical Studies in Oceanography, Vol. 55, No. 3-4, pp. 412-431 (2008). 
10. Manase, S. and Takeda, J., Spatial Data Modeling: Application of Spatial Statistics, Kyoritsu publication. Tokyo, Japan. pp. 148-149 (2005). (in Japanese)

11. Matsukura, R., Mukai, T., Ando, Y., and Iida, K., "The variation of density and sound speed contrasts and theoretical target strength estimation of Euphausia pacifica," Nippon Suisan Gakkaishi, Vol. 7, No. 1, pp. 3844 (2009).

12. Miyashita, K., Aoki, I., and Inagaki, T., "Swimming behaviour and target strength of isada krill (Euphausia pacifica)," ICES Journal of Marine Science, Vol. 53, No. 2, pp. 303-308 (1996).

13. Nakagawa, Y., Endo, Y., and Sugisaki, H., "Feeding rhythm and vertical migration of the euphausiid Euphausia pacifica in coastal waters of north-eastern Japan during fall," Journal of Plankton Research, Vol. 25, No. 6, pp. 633-644 (2003).

14. Nilsson, P. and Ziegler, F., "Spatial distribution of fishing effort in relation to seafloor habitats in the Kattegat, a GIS analysis," Aquatic Conservation: Marine and Freshwater Ecosystems, Vol. 17, No. 4, pp. 421-440 (2007).

15. Rozas, L. P., Minello, T. J., Zimmerman, R. J., and Caldwell, P., "Nekton populations, long-term wetland loss, and the effect of recent habitat restoration in Galveston Bay, Texas, USA," Marine Ecology Progress Series, Vol. 344, pp. 119-130 (2007).

16. Shida, O., Hamatsu, T., Nishimura, A., Suzaki, A., Yamamoto, J., Miyashita, K., and Sakurai, Y., "Interannual fluctuations in recruitment of walleye pollock in the Oyashio region related to environmental changes,' Deep Sea Research Part II, Topical Studies in Oceanography, Vol. 54, No. 23-26, pp. 2822-2831 (2007)

17. Simmonds, E. J., Williamson, N. J., Gerlotte, F., and Aglen, A., “Acoustic survey design and analysis procedure: a comprehensive review of current practice," ICES Cooperative Research Report No. 187, International Councill for the Exploration of the Sea, Copenhagen, Denmark (1992).

18. Takahashi, K., Kuwata, A., Saito, H., and Ide, K., "Grazing impact of the copepod community in the Oyashio region of the western subarctic $\mathrm{Pa}$ - cific Ocean," Progress in Oceanography, Vol. 78, pp. 222-240 (2008).

19. Taki, K., "Vertical distribution and diel migration of euphausiids from Oyashio Current to Kuroshio area off northeastern Japan," Plankton and Benthos Research, Vol. 1, No. 1, pp. 27-35 (2006).

20. Taki, K., "Seasonal and interannual variations in biomass of Euphausia pacifica off north-eastern Japan," Fisheries Science, Vol. 73, No. 5, pp. 281-292 (2007).

21. Tojo, N., Dynamics in Zooplankton Distribution and Associated Ecosystem Interactions off the Pacific Coast of Eastern Hokkaido, Japan, Ph.D. Dissertation, Department of Environmental Science, Hokkaido University, Hakodate, Japan (2009).

22. Tojo, N., Kruse, G. H., and Funk, F. C., "Migration dynamics of Pacific herring (Clupea pallasii) and response to spring environmental variability in the southeastern Bering Sea," Deep Sea Research Part II, Topical Studies in Oceanography, Vol. 54, pp. 2832-2848 (2007).

23. Tojo, N., Shimizu, D., Yasuma, H., Kawahara, S., Watanabe, H., Yonezaki, S., Murase, H., and Miyashita, K., "Quantitative analysis of isada krill (Euphausia pacifica) distribution in the western North Pacific," Bulletin of Japanese Society of Fisheries Oceanogrphy, Vol. 72, No. 3, pp. 165-173 (2008). (in Japanese)

24. Uchikawa, K., Yamamura, O., and Kitagawa, D., "Diet of the mesopelagic fish Notoscopelus japonics (Family: Myctophidae)," Fisheries Oceanography, Vol. 13, No. Suppl.1, pp. 10-20 (2002).

25. Wackernagel, H., Multivariate Geostatistics: an Introduction with Apllication, Springer-Verlag, Heidelberg, Germany (2003).

26. Yamamura, O., Honda, S., Shida, O., and Hamatsu, T., "Diets of walleye pollock Theragra chalcogramma in the Doto area, northern Japan: ontogenetic and seasonal variations," Marine Ecology Progress Series, Vol. 238, pp. 187-198 (2002).

27. Yoshida, H. and Sakurai, Y., "Relationship between food consumption and growth of adult walleye pollock Theragra chalcogramma in captivity," Bulletin of Japan Sea National Fisheries Research Institute, Vol. 50, No. 5, pp. 763-769 (1984). (in Japanese) 